\title{
Kajian Kawasan: Pendekatan Strategis Dalam Penelitian Arkeologi Di Indonesia Dewasa Ini
}

nfn. Mundardjito

Keywords: area, spatial, site, method, theory, archaeology

\section{How to Cite:}

Mundardjito, nfn. Kajian Kawasan: Pendekatan Strategis Dalam Penelitian Arkeologi Di Indonesia Dewasa Ini. Berkala Arkeologi, 15(3), 24-28. https://doi.org/10.30883/jba.v15i3.666

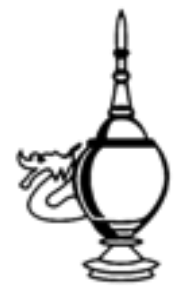

\section{Berkala Arkeologi}

https://berkalaarkeologi.kemdikbud.go.id/

Volume 15 No. 3, 1995, 24-28

DOI: $10.30883 /$ jba.v15i3.666

This work is licensed under a Creative Commons Attribution-NonCommercialShareAlike 4.0 International License. 


\title{
KAJIAN KAWASAN: PENDEKATAN STRATEGIS DALAM PENELITIAN ARKEOLOGI DI INDONESIA DEWASA INI
}

\author{
Mundardjito \\ (Jurusan Arkeologi FS-UI)
}

\section{Arkeologi-Ruang}

Apabila saya atau anda sebagai individu akan memasuki ruang pertemuan ilmiah ini, di pin-tu masuk anda mungkin akan berpikir sejenak sambil melihat ke kiri dan ke kanan, di kursi mana anda akan duduk Kalau anda seorang peserta, dan bukan pejabat penting, anda mungkin tidak akan memilih tempat di barisan kursi paling depan. Anda mungkin akan memilih duduk di barisan kursi agak belakang karena di situ sudah duduk sejum-lah sahabat anda sehingga anda merasa 'hangat' dan sesekali dapat mencuri kesempatan untuk ber-tegur sapa dengan teman karib yang sudah lama tidak bertemu. Atau, jauh sebelum memasuki ru-ang pertemuan, anda sudah memutuskan lebih da-hulu akan duduk di baris kedua agar dapat lebih memusatkan perhatian dalam mendengar uraian para pemakalah tanpa gangguan teman-teman sejawat yang diketahuinya pasti akan mengajaknya berbincang-bincang di luar pokok pembicaraan dalam sidang Pengambilan keputusan untuk menempatkan diri kita dalam satuan ruang itu dipengaruhi atau ditentukan oleh pikiran dan perasaan untuk bersosialisasi dengan sahabatnya atau sebaliknya.

Akan tetapi mungkin saja terjadi kenyataan seperti berikut ini. Ketika anda sampai di pintu ruang sidang, panitia justru meminta secara tegas untuk tidak melakukan pilihan lain kecuali duduk di barisan kursi terdepan karena anda dianggap seorang pemuka masyarakat atau tokoh yang disegani. Dalam keadaan semacam ini anda tentu ti-dak cukup berani untuk menolak permintaan pa-nitia menduduki tempat didepan. Demikianlah du-duknya anda di barisan depan tersebut tidak dipu-tuskan atas dasar keinginan anda tetapi ditentukan oleh aturan yang dibuat panitia, dan anda terpaksa menurut karena menganggap tidak patut melanggar aturan yang sudah ada itu.

Dari cerita pengandaian di atas jelaslah bahwa pengambilan keputusan seseorang untuk mendudukkan atau menempatkan dirinya di dalam suatu ruang dapat dipengaruhi atau ditentukan oleh pikiran dan sikap kita sendiri selaku pribadi, merupakan tanggapan terhadap suatu keadaan yang dihadapi. Pengambilan keputusan seseorang itu didasarkan atas pertimbangan adanya aturan yang telah dibuat dan ditetapkan oleh kesepakatan sekelompok orang. Demikian juga halnya jika sekelompok orang ingin menempatkan dirinya di ruang alam terbuka dengan mendirikan kemah-kemah atau rumah-rumah, mereka akan berpikir dan menanggapi situasi yang dihadapinya untuk kemudian mempertimbangkan atas dasar satu atau beberapa faktor serta memutuskannya secara bersama bagian bentang lahan mana dalam kawasan luas itu yang akan mereka pilih untuk tempat mendirikan rumah-rumah mereka. Pengambilan keputusan dalam pemilihan tempat bermukim itu mungkin bisa disebabkan oleh: pertama, permukaan lahan yang relatif datar, tanahnya subur, dan dekat dengan sungai; kedua, tidak jauh dari tempat yang dipilih itu sudah ada sekelompok orang yang bermukim; ketiga, kepercayaan mereka yang mengharuskan mereka memilih lahan itu untuk tempat bermukim. Demikianlah komunitas manusia dalam pengambilan keputusan untuk menempatkan dirinya di muka bumi bisa didasarkan atas satu atau sejumlah pertimbangan teknologis, sosial, dan ideologis, atau dengan kata lain pertimbangan budaya (kultu-ral). Apabila kita sekarang ingin mengetahui me-ngapa seseorang atau sekelompok orang menem-patkan dirinya dalam ruang pertemuan itu, maka dengan cara mewawancarai mereka kita akan da-pat mengetahuinya secara relatif mudah. Namun dalam pengkajian arkeologi, kita hanya dapat me-ngamati benda-benda mati. Melalui benda-benda arkeologi yang tersebar dalam bangunan dan ha-lamannya, dán benda-benda arkeologi yang terse-bar dalam situs, serta benda-benda arkeologi dan atau situssitus yang tersebar dalam satu wilayah atau kawasan, ${ }^{1}$ para ahli mendeskripsikan dan menganalisis bentuk persebarannya serta hubungannya untuk kemudian menafsirkan dan berusaha menjelaskan mengapa persebarannya demikian

\footnotetext{
Selain istilah 'wilayah' dan 'kawasan', dalam bahasa Indonesia ada pula istilah 'mintakat'. Namun demikian dalam kepustakaan arkeologi di Indonesia lebih ba-nyak digunakan istilah 'wilayah'. Dalam kepustakaan arkeologi berbahasa Inggris ada istilan yang meng-gambarkan tingkat keluasan satuan ruang arkeologi yang lebih besar daripada site yaitu berturut-turut lo-cality, kemudian region, dan akhimya yang paling luas ialah area (lihat Willey dan Phillips,1958:18-20). Agaknya istilah-istilah itu beriaku dalam sistem tak-sonomi arkeologi di Amerika Barat bagian tengah (Mid- Westem Taxonomic System)
} 
Bidang kajian arkeologi yang memusatkan perhatian pada aspek ruang semacam ini dikenal dengan nama arkeologi-ruang (spatial archaeology), yang perkembangannya baru mulai pesat tahun 1960-an dan muncul di antara kesibukan para arkeolog yang ketika itu berkutat menggarap benda-benda arkeologi dari aspek bentuk (formal) dan waktu (temporal). Dalam sejarah perkembangan arkeologi di berbagai bagian dunia pengkajian keruangan terhadap benda-benda arkeologi maupun situs-situs memang datang lebih kemudian daripada pengkajian atas dimensi bentuk (morfologi, tipologi, klasifikasi) dan waktu (kronologi, pertanggalan). Demikian pula yang terjadi di Indonesia. ${ }^{2}$

Selain pergeseran perhatian aspek ruang itu dalam empat dasawarsa terakhir ini di dunia arkeologi terdapat semacam pergeseran tekanan perhatian dari pengkajian atas artefak ke pengkajian atas situs, dan setelah satu dasawarsa kemudian tekanan itu lambat laun bergeser pada pengkajian atas kawasan (region) sebagai satuan ruang yang lebih luas, tempat terletaknya situs-situs. Demikianlah misalnya Dunnel dan Dancey (1983:267) mengatakan:

In the past two decades the investigatory universe for archaelogical field research has gradually shifted from site to region ...."

Perhatian studi arkeologi-ruang lebih banyak ditekankan kepada benda-benda arkeologi sebagai satu kumpulan atau himpunan dalam suatu satuan ruang daripada sebagai satuan-satuan benda tunggal yang berdiri sendiri. Studi arkeologi-ruang dengan demikian tidak memberikan titik berat perhatian kepada benda arkeologi sebagai satu enti-tas (entity), melainkan kepada sebaran (distribu-tion) dari benda-benda dan situs-situs arkeologi, kemudian hubungan (relationship) antara benda dengan benda dan antara situs dengan situs, serta hubungan antara benda atau situs dengan lingkungan fisiknya sebagai sumberdaya. Arkeologi-ruang tidak hanya mengkaji hubungan lokasional atau keruangan antara artefak, tetapi juga dengan dan antara bentuk-bentuk data arkeologi lain yang kesemuanya itu diistilahkan oleh Clarke (1977:11-

\footnotetext{
Menurut hemat peneliti ada tujuh macam variasi kajian arkeologi dilihat dari dimensinya:1) analisis bentuk (formal analysis); 2) analisis umur (temporal analysis), 3) analisis keruangan (spatial analysis), 4) gabungan analisis bentuk dan waktu (formal-temporal analysis), 5) gabungan analisis bentuk dan ruang (formal-spatial analysis), 6) gabungan analisis ruang dan waktu (spatial-temporal analysis), dan 7) gabungan analisis bentuk, ruang dan waktu (formalspa-tial-temporal analysis). Uraian mengenai ketiga di-mensi dalam arkeologi antara lain disajikan dengan baik oleh Albert C. Spaulding (1971)
}

17) sebagai unsur-unsur (elements) yang terdiri dari struktur atau fitur, situs, dan lingkungan fisik yang dimanfaatkan sebagai sumberdaya. ${ }^{3}$ Demikianlah Clarke mendefinisikan secara panjang arkeologiruang sebagai berikut:

"...the retrieval of information from archaeological spatial relationships and the study of the spatial consequences of former hominid activity patterns within and between features and structures and their articulation within sites, site systems and their environments: the study of flow and integration of activities within and between structures, sites and resource spaces from the micro to the semi-micro and macro scales of aggregation (ibid:9).

Dalam sejarah perkembangan arkeologi para ahli arkeologi lambat laun menyadari bahwa data arkeologi tidak hanya diperoleh dari ciri-ciri yang terkandung dalam benda atau situs arkeologi itu sendiri, tetapi juga dapat diperoleh dari hubungan keruangan antara benda-benda atau antara situssitus arkeologi. Arkeologi-ruang berusaha mempelajari sebaran dan hubungan keruangan pada aneka jenis pusat aktivitas manusia, baik dalam skala mikro (micro) yaitu yang mempelajari sebaran dan hubungan lokasional antara benda-benda arkeologi dan ruang-ruang dalam suatu bangunan atau fitur, dan skala meso (atau semi-micro) yaitu mempelajari sebaran dan hubungan lokasional antara artefak-artefak dan fitur-fitur dalam suatu situs, maupun dalam skala makro (macro) yaitu yang mempelajari sebaran dan hubungan lokasional an-tara benda-benda arkeologi dan situs-situs dalam suatu kawasan (lihat sistem analisis unsur-unsur dalam ketiga tingkat satuan ruang. Clarke 1977:11-16). Istilah kajian kawasan dalam judul makalah ini sidak lain adalah kajian arkeologi-ruang skala makro sebagaimana dikemukakan di atas.

\footnotetext{
Bidang lahan tertentu dalam lingkungan fisik suatu pemukiman yang dimanfaatkan oleh penduduk guna memenuhi kebutuhannya diistilahkan oleh Clarke se-bagai resource space. Bidang lahan lain yang meski-pun terletak di dekatnya namun tidak pernah dikunju-ngi maupun dimanfaatkan oleh manusia masa lalu, tidak dapat dikatakan sebagai 'ruang sumber-daya'. Dicontohkan oleh Clarke bahwa area di seki-tar pera-pian, dapur atau di serambi rumah misalnya dapat di-nyatakan sebagai ruang sumberdaya dalam pemu-kiman mikro, sedangkan bidang lahan lain sepeıti lahan pertanian, padang rumput atau tempat penam-bangan mineral dalam satuan ruang yang lebih luas dapat dikatakan sebagai ruang sumberdaya pemuki-man meso, atau ruang sumberdaya pemukiman ma-kro (Clarke 1977:9)
} 
Penelitian arkeologi-ruang tidak hanya melakukan analisis terhadap situs pemukiman dalam arti tempat hunian, tetapi mencakup semua tempat pusat aktivitas dari komunitas manusia masa lalu seperti situs kubur, situs upacara, situs gua, situs pasar, dan situs eksploitasi sumberdaya alam. Oleh sebab itu arkeologi-ruang tidak sinonim de-ngan arkeologi - permukiman (Clarke, 1977:9). Demikianlah dinyatakan secara tegas oleh Clarke (1977:1) bahwa kajian arkeologi-ruang lebih luas lingkupnya daripada aneka macam kajian yang sudah dikenal sebelumnya dalam lingkungan arkeologi dan merupakan bentuk-bentuk studi arkeologiruang dalam skala serta konteks tertentu (seperti site system analysis, regional studies, territorial analysis, locational analysis, catchment area studies, distribution mapping, density studies, withinsite and within-structure analysis, dan stratigraphic studies). ${ }^{4}$

- Sebagian besar ahli arkeologi Indonesia masih beranggapan bahwa settlement archaeology (arkeologi - permukiman) hanya mengkaji settlement site (situs pemukiman dalam arti situs hunian atau situs tempat tinggal). Anggapan semacam ini tidak janggal terjadi di negara kita karena di Eropa dan Amerika pun kesalahapahaman ini juga dijumpai. Demikianlah Ruth Tringham (1972:xix) misalnya pernah menyatakan bahwa konsep settlement dan peng-gunaan istilah tersebut -seperti dalam istilah settlement site-- telah dipakai sejak abad XIX untuk pengertian situs arkeo-logi yang mengandung sisa habitasi. Para ahli arkeo-logi, khususnya di Eropa, melanjutkan penggunaan istilah settlement dengan konotasi semacam itu un-tuk menunjukkan perbedaan yang konkret dengan jenis situs lain seperti ritual site (situs upacara), burial site (situs kubur), dan quarry site (situs tam-bang). Dengan demikian pengertian distribution of settlements (sebaran pemukiman) dalam arkeologi di Eropa merujuk kepada pengertian sebaran (geo-grafi) dari tinggalan arkeologi pada situs-situs pemu-kiman yang merupakan bukti-bukti diselenggarakan-nya kegiatan domestik dari komunitas manusia masa lalu. Penggunaan istilah settle-ment dengan penger-tian serupa itu menurut Tring-ham mungkin merupa-kan awal dari kesalahpahaman sementara ahli ar-keologi Eropa dan Amerika (sejak 1953) yang meng-garap studi settlement, settlement pattems, dan set-tlement archaeology. Periksa pula tulisan Rouse mengenai konsep pola permukiman dan penggu-naannya dalam penelitian arkeologi (1972:95--107). Di Amerika, menurut Tringham, settlement archaeolo-gy adalah studi mengenai hubungan-hubungan so-sial dengan menggunakan data arkeologi (periksa selanjutnya Trigger 1967:149, 151, 153), yang tidak selalu harus berupa situs hunian. Bahkan Leo $S$. Kle-jn memberi istilah terhadap kajian hubungan sosial serupa ini sebagai 'sociological archaeology' atau 'social archaeology' (periksa Klejn, 1977:9). Perlu di-kemukakan di sini bahwa konsepsettlement

\section{Masalah Penelitian Arkeologi - Ruang di Indonesia}

Kegiatan survei arkeologi di Indonesia untuk menemukan situs-situs sudah berlangsung lama sejak masa penjajahan Belanda sebelum tahun 1880 -an. ${ }^{5}$ Hasil survei itu telah disusun dengan baik oleh Verbeek (1891) dan dipuji oleh Krom sebagai salah satu laporan inventarisasi kepurbakalaan ilmiah pertama yang terbaik dan terlengkap di dunia ketika itu (Krom, t.t.280), karena memuat pemerian situs beserta pustaka acuan, dan peta lokasi situs-situs meskipun dalam skala 1:500.000. Pekerjaan ini dilanjutkan oleh Bosch, ljzerman, Knebel, Hoepermans dan laih-lain, yang kemudian diterbitkan oleh Krom tahun 1915, dan kemudian Bosch tahun 1918. Sayangnya buku-buku inventaris itu hanya memuat situs-situs yang ada di pulau Jawa (dan Madura). Meskipun jumlah situs yang didaftar pada tahun-tahun berikutnya makin banyak, tetapi sayangnya lagi baik buku Krom mau-

archaeo-logy dan settlement pattem dipakai secara sistema-tis untuk pertama kali terhadap bukti-bukti arkeologi oleh Willey (1953). Willey berpendapat (1953:1) bah-wa settlement archaeology ialah studi atas data ar-keologi yang berkaitan dengan pengaruh lingkungan alam, tingkat teknologi, dan berbagai pranata interak-si serta kontrol sosial yang dipertahankan oleh kebu-dayaan. Lebih jauh Leo S. Klejn menegaskan bahwa: "Settlement archaeology, which shifted attention from typological studies and revelation of intercultu-ral differences, similarities, and contacts to the stu-dy of a 'locality'-the remains of a single face-to-face group-was a consistent development of the ideas of the contextual school" (1977:9).

Sejak tahun 1901 di Indonesia sudah dibentuk satu badan non pemerintah yang pada pokoknya bertugas menangani penelitian arkeologi yaitu Commissie in Nederlandsch-Indie voor Oudheidkundig Onder-zoek op Java en Madoera, yang kemudian tugas dan kewajibannya itu diambil alih pada tahun 1913 oleh badan pemerintah bernama Oudheidkundige Dienst in NedertandschIndie (periksa Soekmono 1977:1-25). Selanjutnya setelah kemerdekaan badan ini berturut-turut bernama Dinas Purbakala Republik Indonesia pada tahun 1953, kemudian berganti nama menjadi Lembaga Purbakala dan Peninggalan Na-sional (LPPN) dalam tahun 1963. Pada tahun 1975 lembaga ini dipecah menjadi dua yaitu: (1) Pusat Pe-nelitian Purbakala dan Peninggalan Nasional (PUS-PAN), dan (2) Direktorat Sejarah dan Purbakala (DSP), yang akhirnya pada tahun 1980 berubah nama menjadi Pusat Penelitian Arkeologi Nasional (PUSPAN, kemudian disingkat PUSLIT ARKENAS), dan Direktorat Perlindungan dan Pembinaan Pening-galan Sejarah dan Purbakala (DP3SP, lalu disingkat DITLINBINJARAH). 
pun Bosch tidak dilengkapi dengan peta lokasi situs-situs dan juga tidak menyatakan keterangan mengenai koordinatnya. Akibatnya sukar bagi kita untuk melacak kembali lokasi situs-situs yang sudah pernah ditemukan seratus tahun yang lalu. Oleh karena itu sampai saat ini tidak dapat diketahui secara pasti berapa jumlah situs arkeologi yang sudah pernah ditemukan, di mana saja semua situs itu terletak. pada bentuk permukaan bumi seperti apa, bagaimana sebarannya, serta hubungannya satu sama lain dan hubungannya dengan aspek lingkungan alam. Padahal keterangan mengenai lokasi situs, frekuensi, luas sebaran, kepadatan, bentuk konfigurasi sebaran, dan korelasinya dengan sumberdaya alam merupakan data dasar yang biasa digunakan dalam studi arkeologi-ruang skala kawasan untuk mengetahui dan memahami berbagai hal mengenai perilaku dan gagasan keruangan masyarakat masa lalu. Apa yang diutarakan di atas hanya sekedar menunjukkan bahwa aspek keruangan dari benda arkeologi dan situs sejak lama belum mendapat perhatian yang selayaknya di Indonesia.

Relatif sedikit ahli arkeologi kita yang terjun menekuni bidang kajian arkeologi-ruang, dan oleh karena itu belum banyak hasil penelitian yang dapat dijadikan bahan acuan atau bahan banding yang memadai. Oleh sebab itu pula masuk akal kiranya jikalau di negara kita data dasar yang biasa diperlukan dalam kajian arkeologi-ruang belum tersedia, atau kalau pun ada belum cukup siap untuk dapat digunakan secara langsung dalam penelitian khusus semacam ini. ${ }^{6}$ Pada dewasa ini para peneliti arkeologi-ruang di Indonesia harus berupaya keras, dan menggunakan sebagian besar waktunya untuk melacak lebih dahulu informasi keruangan dari benda-benda dan situs-situs arkeologi yang pemah diketahui atau disebut dalam laporan-laporan inventarisasi kepurbakalaan, kemudian mendaur ulang dan menambahnya dengan data yang lebih lengkap dan lebih khusus, serta melengkapinya dengan data baru sebelum dapat diolah dalam tahap analisis untuk memungkinkan tercapai-

\footnotetext{
6 Data arkeologi-ruang di Indonesia pada hakikatnya memiliki kelemahan yang disebabkan oleh sekurang-kurangnya lima hal: 1) kelemahan pencatatan yang ti-dak kontekstual; 2) kelemahan dalam sistem penca-tatan inventarisasi tinggalan purbakala beserta situs-nya yang kurang memperhatikan data lokasional yang cermat serta kurang memperhatikan upaya perbaik-an pencatatan secara berkala; 3) ketahanan dari peninggalan purbakala di situs-situs karena kegiatan alam maupun manusia seperti rusak, hilang, dan dipin-dahkan tanpa direkam; 4) ketiadaan atau kelangkaan pertanggalan mutlak; dan 5) kekurangan perhatian dalam pembuatan peta sebar benda dan situs arkeo-logi yang akurat
}

nya tujuan penelitian dengan hasil yang memadai. Dalam pada itu arkeologi-ruang seperti dikatakan Clarke:

"... needs the elaboration of a common range of useful elements, assumptions, theory, models, methods and problems to be tested, reassessed and extended in dynamic and integrated case studies ... "(ibid:7).

Oleh sebab itu sudah waktunya bagi kita sekarang untuk melangkah lebih jauh dalam kajian kawasan arkeologi sehingga apa yang dikemukakan Clarke dapat sedikit dilaksanakan

\section{Metodologi}

Sebagaimana diuraikan dalam bab terdahulu kita telah dapat mengidentifikasi sekurang-kurangnya empat sasaran pokok kajian dalam studi arkeologi - ruang. Pertama, mengkaji aspek informa-si keruangan dari situs-situs arkeologi. Kedua, mengkaji sebaran dari sejumlah besar benda dan situs arkeologi. Ketiga, mengkaji hubungan antara situs-situs arkeologi, dan hubungan antara situssitus itu dengan sumberdaya alam di sekitarnya. Keempat, mengkaji semua itu dalam satuan dae-rah penelitian yang luas (kawasan).

Secara teoritis sebaran situs-situs, yang polanya dapat diamati langsung secara empirik (observed pattern), dapat dianggap sebagai satu produk yang terwujud secara akumulatif dalam kurun waktu tertentu. Sebaran situs itu diduga tidak bersifat acak, melainkan berpola, karena pada dasamya masyarakat tidak berperilaku acak dalam menempatkan situs, tetapi dalam batas-batas tertentu mengikuti aturan umum yang berlaku dalam masyarakat (normative) (Watson et al. 1971:61). Pola sebaran situs diduga merupakan wujud konkret dari pola gagasan dan pola perilaku masyarakat masa lalu mengenai penempatan, pengaturan dan penyebaran situs-situs di daerah penelitian. Pemolaan keruangan dari situs-situs arkeologi dapat mencerminkan pemolaan aktivitas manusia masa lalu (Schiffer, 1972:156) yang didasarkan atas satu atau sekumpulan pertimbangan teknolo-gisekologis, pertimbangan perilaku sosial, dan pertimbangan ideologis.

Karena kajian arkeologi-ruang skala kawasan belum merupakan hal yang biasa dalam tradisi penelitian arkeologi Indonesia, maka dalam tahap awal pengkajian mungkin lebih baik kita tidak semata-mata mengaitkannya secara kaku dengan salah satu teori interpretasi yang umum dikenal dalam penelitian arkeologi di dunia barat. Sebaiknya kita lebih dulu meningkatkan kemampuan kita memperoleh data keruangan dari satu kawasan yang mudah diperoleh dan menguji-coba teori dan metode interpretasi yang sesuai dengan hakikat data arkeologi Indonesia. 
Untuk mencapai sasaran pokok itu peneliti harus pertama-tama mengetahui sebanyak mungkin jumlah situs arkeologi yang ada dan pernah ada di daerah penelitian untuk memberi kemung-kinan dapat ditariknya suatu generalisasi yang me-madai, baik melalui data kepustakaan maupun da-ta lapangan dengan metode survei lapangan yang bukan ekskavasi (non-digging research). Kedua, mengetahui secara tepat lokasi dari situs-situs tersebut disertai keterangan mengenai derajat-menitdetiknya pada bujur timur dan lintang selatannya (bukan hanya nama tempat dan nama administrasinya saja seperti yang dihasilkan oleh program inventarisasi kita pada umumnya) sebagai bahan untuk membuat peta sebaran situs secara akurat. Ketiga, membuat peta sebaran situs arkeologi di daerah penelitian berdasarkan peta topografi dan hasil dari pengumpulan data mengenai jumlah serta keletakan astronomisnya sebagai bahan untuk mengetahui bentuk konfigurasi situs, apakah susunannya itu berkelompok, menyebar rata, acak, linier, padat, jarang dan sebagainya. Keempat, mengetahui variabel-variabel lingkungan yang ada di daerah penelitian sebagai dasar pembuatan peta sebaran potensi sumberdaya alam biotik dan abiotik (seperti sisa flora dan fauna, bentuklahan, jenis tanah, batuan, tekstur tanah, kedalaman efektif tanah, ketinggian tempat, kemiringan permukaan lahan, ketergenangan, ketererosian permukaan tanah, kedalaman muka airtanah, permeabilitas tanah, jarak situs terhadap sungai terdekat, dan jarak situs terhadap mata air terdekat) Kelima, membuat peta sebaran dari aspek-aspek sumberdaya alam tersebut di atas sebagai bahan untuk menganalisis hubungan-hubungan antar situs. Keenam, mengkaji hubungan antara keletakan dan sebaran situs-situs dengan keletakan dan sebaran aspekaspek sumberdaya alam untuk mengetahui pola korelasi dan kesesuaian di antara kedua pola sebaran itu. Ke-tujuh, menafsirkan pola-pola hubungan itu untuk mengetahui pola pemanfaatan sumberdaya lahan dan air pada masa lalu dan variabel-variabel lingkungan apa yang merupakan faktor penting atau faktor penentu (Trigger, 1978:16793). Dengan demikian diharapkan kita akan memperoleh sedikit pengetahuan tentang penerapan pertimbangan teknologis-ekologis yang dilakukan oleh masyarakat masa lalu beserta variasi pilihannya, atau dengan perkataan lain berusaha menafsirkan kearifan lingkungan masyarakat masa lalu dalam hal penempatan situs-situs di daerah penelitian. Diharapkan pengetahuan ini dapat dipergunakan sebagai bahan penyusunan hipotesis yang lebih kuat dasarnya untuk kemudian dikajiulang dalam penelitian berikutnya (generative), sehingga siklus penelitian bergulir dengan tingkat analisis yang semakin tinggi dan semakin mendalam.

Manfaat lain yang diperoleh dari penelitian semacam ini ialah menambah pengetahuan dan pengalaman dalam melaksanakan penelitian arkeologi-ruang yang sesuai dengan hakikat data dan tingkat penelitian arkeologi di Indonesia, serta mencoba mengembangkan metode dan teori arkeologi khususnya metode survei arkeologi-ruang skala kawasan. Metode survei permukaan arkeologi (site surface survey) yang pada dasarnya relatif jauh lebih murah daripada biaya ekskavasi, mampu menghasilkan satu tingkat pengetahuan tertentu yang patut dipertimbangkan. Ekskavasi sebagai satu metode penelitian biaya tinggi, memang tidak selalu harus digunakan dalam setiap penelitian arkeologi. Sebaliknya jika diterapkan secara tepat, metode survei arkeologi juga dapat menghasilkan kemanfaatan yang bernilai tinggi. Bahkan dalam dua dasawarsa ini terdapat kecenderungan yang besar bahwa hasil penelitian dengan metode survei tidak kalah pentingnya dari hasil penelitian ekskavasi. Demikian misalnya Stephen Plog. Fred Plog dan Walter Wait menegaskan dalam salah satu karangannya sebagai berikut:

"... Some archaeologists are now devoting most of their field effort to survey work, and in some parts of the wortd the relative im-portance of survey and excavation as field techniques is approaching equality. Although the growing importance of cultural resources surveys in the United States is in part res-ponsible for this trend ... as well as the gro-wing cost of excavation and its heavy impact on the available archaeological record, has markedly increased the archaeological po-tential surveys...." (1978:383).

Penelitian semacam ini dapat menghasilkan peta sebaran situs yang cukup akurat, dan dengan informasi yang ada di dalamnya sudah tentu dapat dimanfaatkan untuk: 1) merencanakan strategi penelitian arkeologi-ruang skala makro yang lebih mantap, baik di daerah penelitian ini maupun di daerah-daerah lain, atau suatu strategi penelitian yang lebih rinci untuk memperdalam dan mempertajam permasalahannya dalam skala ruang yang lebih kecil (meso dan mikro), bahkan dapat juga disusun strategi penelitian yang sifatnya komparatif dan diakronis untuk memahami proses-proses budaya; 2) merencanakan strategi perlindungan dan pengamanan situs-situs dengan cara pewilayahan daerah-daerah purbakala (zoning) guna penentuan skala prioritas pengamanan terhadap dampak negatif; serta 3) merencanakan strategi pemanfaatan situs-situs sebagai sumberdaya ekonomi dalam rangka pengembangan kepariwisata-an dan pengembangan daerah. 


\section{REFERENSI}

Willey, Gordon R. and Phillips, Phillip. Method and theory in American archaeology. Chicago : University of Chicago Press.

Dunnell, Robert C., and William S. Dancey. "The Siteless Survey: A Regional Scale Data Collection Strategy." Advances in Archaeological Method and Theory 6 (1983): 267-87. http://www.jstor.org/ stable/20210070.

Clarke, D.L. and Dr David Clarke . 1977. Spatial Archaeology. UK: Academic Press.

Spaulding, Albert C. (1960). "The dimensions of archaeology". In Gertrude E. Dole; Robert L. Carneiro (eds.). Essays in the science of culture in honor of Leslie A. White. New York: Crowell. pp. 437-56. [Reprinted in Man's imprint from the past: readings in the methods of archaeology, ed. James Deetz (Boston: Little, Brown, 1971), 23-39.]

Tringham, Ruth. 1972. Man, settlement and urbanism: proceedings of a meeting of the Research Seminar in Archaeology and Related Subjects held at the Institute of Archaeology, London University. Duckworth, London.

Trigger, Bruce G. "Settlement Archaeology. Its Goals and Promise." American Antiquity 32, no. 2 (1967): 149-60. doi:10.2307/277900.

Klejn, Leo (1977). "A Panorama of Theoretical Archaeology". Current Anthropology. 18 (1): 1-42. doi:10.1086/201846. JSTOR 2741222

PHILLIPS, P. and WLLEY, G.R. (1953), Method and Theory in American Archeology: An Operational Basis for Culture-Historical Integration. American Anthropologist, 55: 615-633. https:// doi.org/10.1525/aa.1953.55.5.02a00030

Verbeek, R. D. M. (1891). Voorlopig bericht over den Nummulieten, Orbitoiden en Alveolinen van java, en over den ouderdom der gesteenten waarin zij optreden. Natuurkundig tijdschrift voor Nederlandsch Indië, available online at https:// www.biodiversitylibrary.org/page/39561419

Krom, N.j. 1915. Rapporten Van Den Oudheidkundigen Dienst In Nederlandsch Indie 1914 Inventaris Der Hindoe Oudheden. Batavia:Albrecht \& Co.

Bosch, FDK. 1918. Rapporten van den Oudheidkundigen Dienst in Nederlandsch-Indie 1915 : Inventaris der Hindoe-oudheden. Batavia:Albrecht \& Co.
Soekmono, 1977. Candi Fungsi dan Pengertiannya. Semarang: IKIP Semarang.

Watson, Patty jo. \& LeBlanc, Steven A. \& Redman, Charles L. 1971. Explanation in archeology; an explicitly scientific approach. New York: Columbia University Press

Schiffer, Michael. B. 1972. Archaeological Context and Systemic Context. American Antiquity, Vol. 37. No. 2. (Apr., 1972), pp. 156-165.

Trigger, Bruce. G. 1978. Time and Traditions: Essays in Archaeological Interpretation. Edinburgh: Edinburgh University Press 